\title{
Conjugal Parkinson's disease - real or chance?
}

Bettina Balint, $\mathrm{MD}^{1,2}$, Roberto Erro, $\mathrm{MD}^{3}$, Florian Brugger, $\mathrm{MD}^{1,4}$, Ashwani Jha, MD, $\mathrm{PhD}^{1}$, Amit Batla,

$$
\mathrm{MD}^{1} \text {, Christos Ganos, } \mathrm{MD}^{1,5} \text {, Elena Antelmi, } \mathrm{MD}^{1,6} \text {, Kailash P. Bhatia, FRCP }{ }^{1}
$$

${ }^{1}$ Sobell Department of Motor Neuroscience and Movement Disorders, UCL Institute of Neurology, Queen Square, London, UK.

${ }^{2}$ Department of Neurology, University Hospital Heidelberg, Heidelberg, Germany

${ }^{3}$ Dipartimento di Scienze Neurologiche e del Movimento, Università di Verona, Verona, Italy

${ }^{4}$ Department of Neurology, Kantonsspital St. Gallen, St. Gallen Switzerland

${ }^{5}$ Department of Neurology, University Medical Center Hamburg-Eppendorf (UKE), Hamburg,

Germany

${ }^{6}$ Department of Biomedical and Neuromotor Sciences, Alma Mater Studiorum, University of Bologna, Bologna, Italy

Corresponding author:

Prof Kailash Bhatia

Sobell Department of Motor Neuroscience and Movement Disorders

UCL Institute of Neurology

33 Queen Square

WC1N 3BG London

UK

Email: k.bhatia@ucl.ac.uk

Telephone: +4402034488723

Word count: 500

Word count abstract: 0

Number of references: 7

Number of tables: 1

Number of figures: 0

Supplemental Data: Video 
Sir,

We read with great interest the publication by Rajput and colleagues, reporting the autopsy findings of five couples with conjugal parkinsonism (including three with atypical parkinsonism like multisystem atrophy (MSA) or progressive supranuclear palsy (PSP), but only two with Parkinson's disease) and concluding that neither a prion-like transmission nor shared environmental factor seem to play a role in the pathogenesis of Parkinson's disease. ${ }^{1}$ They further suggest that the risk of parkinsonism in unrelated couples is similar to that in the general population.

Here we present our own data and also a literature review, and suggest that the above conclusions may be premature and prospective large cohort studies are needed. Parkinson's disease (PD) is characterised by $\alpha$-synuclein accumulation with a prevalence rate in the UK population $>65$ years of 12.1/1000. Environmental factors have been continuously implicated in its pathogenesis, whereas current interest focuses on the gut-brain axis and on the so-called prion-hypothesis of $\alpha$-synuclein spread. There is accumulating evidence suggesting that $\alpha$-synuclein may be responsible for initiating $\mathrm{PD}$, and that its spreading is associated with disease progression.

$\alpha$-synuclein is present in saliva and plasma of PD patients, and has been shown in animal models to be taken up and transferred by neurons. In prion disease itself, body fluids like saliva are considered to be of low infective risk. Thus, the question arose if conjugal PD is a chance finding or indicative of PD could being a communicable, prion-like disease.

In this light we would like to present the two couples with conjugal PD amongst our cohort of 160 PD patients and discuss the implications of this finding.

Couple_\#1 (video): This 79-year-old man has been carer of his 77-year-old wife, diagnosed with PD 15 years earlier. They have been together for 55 years and reported residential, non-occupational pesticide exposure. When he accompanied her to our clinic, he mentioned having slowed down lately. He had lost his sense of smell for several years and, more recently, had developed dream enactment. On examination, he had hypomimia and asymmetric bradykinesia. A DaTSCAN was abnormal.

Couple_\#2: This 80-year-old man has been taking care of his wife, affected with PD for five years. They had been married for 40 years. Six months ago, she noted a tremor of his jaw and his leg. In the past, he has had dream enactment. On examination, he had hypomimia, rest tremor, bradykinesia and rigidity of the left arm and leg. His gait was small stepped. A DaTSCAN was abnormal.

None of the patients had consanguineous parents or a family history of PD.

Based on aforementioned prevalence rates, the chance of two spouses having PD would be $0.014 \%$ in the general population. Thus, the point prevalence of conjugal PD in our sample $(1.25 \%$; $95 \% \mathrm{Cl}$ : [$0.47 ; 2.97])$ exceeds the expected prevalence by far and implies a risk ratio of $83.33(95 \% \mathrm{Cl}$ $19.21 ; 361.440)$. The conjugal occurrence of $\alpha$-synucleinopathies has been previously noted (table), yet mostly without putting these observations into the context of prevalence rates. Most casecontrol studies in PD did not systematically assess spouses for PD. Those reporting no cases of conjugal PD had some methodological limitations in this regard, like assessment by questionnaire only, or small sample size. ${ }^{2,3}$ Two studies, however, documented increased conjugal PD/parkinsonism rates of $0.43 \%$ and $0.48 \%$, respectively, despite a study design not targeting sensitive detection of such cases. ${ }^{4,5}$ Besides, such figures may be an underestimate considering that some included patients may have been single. Our observation shares some limitations with previous reports, including the small sample size. This is reflected by large Cls, indicating low accuracy. Yet, a risk ratio of about 20 (inferior limit) would still appear impressive. However, such statistics critically depend on the theorem of large numbers, which we acknowledge is a limitation here. 
Thus, the question remains if conjugal PD is a real or a chance finding.

Rajput and colleagues ${ }^{1}$ argue that in conjugal parkinsonism, both partners should have the same pathological phenotype if the disorder was transmittable or caused by shared environmental risk factors. Thus, the pathological discordance of some of their couples (e.g. MSA and PD; PSP and tauopathy with features of PSP and CBD) would refute such hypotheses. However, probably it can't be excluded that individual predisposition might modify the clinical and pathological phenotype.

We feel before assuming definite conclusion, a systematic approach with large cohorts would be required to re-appraise this matter, which has important implications.

Ramani M, Saur DP, Rabin M, Kurlan R. 1 couple

Conjugal and familial Lewy body

Husband PD, onset age 64 years

disorders: a report of one family.

Wife DLB, onset age 61 years

Parkinsonism Relat Disord.

013;19(4):498.

Shared environmental risk factors:

$>30$ years history of

wellwater intake; molybdenum mined in their residential county

Family history:

PD (husband's sister)

9 couples (PD/PD)

Willis AW, Sterling C, Racette BA.

recruited between 1994-2005

Conjugal Parkinsonism and Parkinson

disease: a case series with

Duration of cohabitation

environmental risk factor analysis.

Parkinsonism Relat Disord.

010;16(3):163-6.

prior to symptom onset in the firstly affected spouse:

average 39.9 years $( \pm 9.2)$

(in our cases: 35 and 40 years)

Time to disease onset in the second spouse

average $4-9$ years, range $1-13$ years

(in our cases: 5 and 15 years)

Shared environmental risk factors:

residential, non-occupational pesticide and heavy metal exposure in $77.8 \%$

(7/9) of couples

(in our cases: residential, non-occupational pesticide use (gardening) in couple

\#1)

\begin{tabular}{|c|c|}
\hline $\begin{array}{l}\text { Miwa H, Kondo T. Conjugal } \\
\text { parkinsonism: multiple system atrophy } \\
\text { and Parkinson's disease. Parkinsonism } \\
\text { Relat Disord. 010;16(3):232. }\end{array}$ & $\begin{array}{l}1 \text { couple } \\
\text { Wife: PD, onset } 62 \text { years } \\
\text { Husband: multisystem atrophy } \\
\text { Shared environmental risk factors: } \\
\text { parathion use for gardening for } 10 \text { yrs }\end{array}$ \\
\hline $\begin{array}{l}\text { Counihan TJ. Conjugal Parkinson's } \\
\text { disease. Lancet. 2003;361(9353):252. }\end{array}$ & $\begin{array}{l}1 \text { couple (PD/PD) } \\
\text { no further details }\end{array}$ \\
\hline Strang RR. Conjugal parkinsonism. Dis & $\begin{array}{l}2 \text { couples (PD/PD) } \\
\text { observed in } 897 \text { cases of PD (bachelors excluded) }\end{array}$ \\
\hline
\end{tabular}


Table: Overview of previously reported cases of conjugal $\alpha$-synucleinopathies.

\section{References}

1. Rajput AH, Ferguson LW, Robinson CA, Guella I, Farrer MJ, Rajput A. Conjugal parkinsonism Clinical, pathology and genetic study. No evidence of person-to-person transmission. Parkinsonism Relat Disord. 2016 Jul 26. pii: S1353-8020(16)30275-9.

2. Ubeda JV. Null hypothesis of husband-wife concordance of Parkinson's disease in 1,000 married couples over age 50 in Spain. Neuroepidemiology. 1998;17(2):90-5.

3. Bonifati V, Fabrizio E, Vanacore N, De Mari M, Meco G. Familial Parkinson's disease: a clinical genetic analysis. Can J Neurol Sci. 1995 Nov;22(4):272-9.

4. Pals P, Van Everbroeck B, Grubben B, Viaene MK, Dom R, van der Linden C, Santens P, Martin $\mathrm{JJ}$, Cras P. Case-control study of environmental risk factors for Parkinson's disease in Belgium. Eur J Epidemiol. 2003;18(12):1133-42.

5. Rocca WA, Peterson BJ, McDonnell SK, Bower JH, Ahlskog JE, Schaid DJ, Maraganore DM. The Mayo Clinic family study of Parkinson's disease: study design, instruments, and sample characteristics. Neuroepidemiology. 2005;24(3):151-67.

\section{Acknowledgement}

Web resources:

Parkinson's UK. http://www.parkinsons.org.uk/sites/default/files/parkinsonsprevalenceuk 0.pdf. 2009. Accessed February 18, 2016.

\section{Supplementary material: Video.}

The video shows couple 1. He has hypomimia, reduced arm swing, reduced shoulder shrug and bradykinesia (left more than right). She has classic levodopa-induced, generalised dyskinesia, hypomimia, reduced shoulder shrug on the left more than on the right, and a subtle rest tremor on the left. 


\section{Author contributions:}

Dr. Balint - Study concept and design, acquisition of data, analysis and interpretation, writing the first draft, critical revision

Dr. Erro - analysis and interpretation, critical revision of the manuscript for important intellectual content

Dr. Brugger - acquisition of data, critical revision of the manuscript for important intellectual content

Dr. Jha - critical revision of the manuscript for important intellectual content

Dr. Batla - critical revision of the manuscript for important intellectual content

Dr. Ganos - critical revision of the manuscript for important intellectual content

Dr. Antelmi- critical revision of the manuscript for important intellectual content

Prof. Bhatia - Study concept and study supervision, critical revision of the manuscript for important intellectual content

\section{Author disclosures:}

None of the authors has any disclosures, or any conflict of interest, related to the present study. Dr. Balint held a research grant from the Gossweiler foundation.

Dr. Erro reports no disclosures.

Dr. Brugger reports no disclosures.

Dr. Jha reports no disclosures.

Dr. Batla reports no disclosures.

Dr. Ganos reports no disclosures.

Dr Antelmi reports no disclosures.

Prof Bhatia reports no disclosures related to the manuscript. He receives royalties from Oxford University press and a stipend for MDCP editorship, holds grants from NIHR RfPB, MRC Welcome Strategic grant (WT089698), PD UK (Ref. no.: G-1009), and Horizon 2020 EC grant Propag-Aging. He has received honoraria/financial support to speak / attend meetings from GSK, BoehringerIngelheim, Ipsen, Merz, Sun Pharma, Allergan, Teva Lundbeck and Orion pharmaceutical companies. 